\title{
The Impact of Housing Issue on the Well-being of Middle-Income Group
}

\section{Dr. Shadiya Mohamed Baqutayan}

\author{
Perdana School of Science, Technology and Innovation Policy, Universiti Teknologi Malaysia \\ Level 6, Menara Razak, 54100, Jalan Sultan Yahya Petra, Kuala Lumpur
}

Doi:10.5901/mjss.2015.v6n6s1p522

\begin{abstract}
Dwellers that are facing one housing issue, typically, face numerous risky housing circumstances that threaten the arrangement of their outcomes. Additionally, experiencing multiple critical housing issues can increase the negative effects that such conditions have on the whole members; physically, psychologically and emotionally. This paper discusses the effect of housing issues on the psychology wellbeing of middle-income group in Malaysia. The purpose is to understand the impact of such difficulties like housing price, safety and security, housing quality, transportation, schools and economic development on the stress and wellbeing of people in Malaysia. Simple random sampling was assigned to a large number of middle-income residents in Malaysia. The accumulated data were analysed and the descriptive statistics were used to evaluate prevalence of housing issues, housing stress and wellbeing. The finding indicated small but significant positive relationship between housing conditions and wellbeing. The housing stresses in this study are those caused by transportation, housing quality, and economic development. Hence, this research supports the critical link between good housing conditions like safe, secure, easy to transport and affordable and positive health outcome.
\end{abstract}

Keywords: Housing, Housing Stress, Housing issues, wellbeing

\section{Introduction}

Issues of housing and wellbeing have become increasingly important in developed countries, and the home environment is of tremendous significance to human beings. The relationship between housing issues, stress and health has been of policy interest since 1842 when Chadwick noted the low life expectancy of cellar dwellers. The 1998 Acheson Report identified housing and environment as an importance area for reducing health inequalities; concerns repeated a decade later by Marmot in 2010 (Barnes et al, 2013). According to Jackson (2003), housing issue has been acknowledged as one of the main problem that affects the wellbeing of middle-income groups.

Housing is very fundamental to the welfare, survival and health of individuals, but the common feeling these days is that houses are becoming too expensive, and affordable housing is an issue that stresses the public. Housing affordability has become the main issue in housing sector as the house price and living cost continue to increase especially in urban area. In this concern much effort has been made by the Malaysian government to address the issue of affordable housing. Nevertheless, the aspiring of these commitments, public policy has paid little attention to the effect of home on dweller's wellbeing. Furthermore, housing issues can have an adverse effect on the family's psychological wellbeing; therefore, the actual relationship between housing issue and wellbeing need to be addressed.

\section{Housing Issue and Affordability}

It is indeed a difficult task to define the actual housing issue that contribute to housing stress, therefore, Department for Communities and Local Government (2012) reported housing issues as the house that lack the affordability, community safety, transportation \& planning, economic development, and neighbourhood development. Recently, Litman (2015) indicated that the most housing stresses are living in more compact neighbourhoods, traveling by walking, cycling and public transit travel, and crime problems. And NGA Center for Best Practice (2007) reported on housing challenges; that is inextricably connected to a variety of other policy issues like transportation, education, and economic development. From these reports, researchers grouped housing issues into six categories of factors that contributed to housing stress. These are housing price, safety and security, housing quality, transportation issue, school choice, and economic development. The purpose is to understand the effect of these issues on dwellers' wellbeing, and it is expected that if a household were in housing stress, the household's wellbeing would be lower than those without stress. According to Robinson et al., (2006), housing price, housing conditions, temporary accommodation, housing size, and housing tenure 
raise issues always affect the health and wellbeing of dwellers.

"Affordability" as a concept is very generic and could have different meanings for different people based on differences in income levels and needs. However, defining "affordability" in term of financial based is not the only concern that people cares; there are thing needs to be consider. For example, should households that spend a small fraction of their income on housing but that live in a substandard home or in an unsafe neighbourhood or at great distances from their jobs be construed as having affordability problems? If so, then which such households ought to be counted? According to Belsky, Goodman, \& Drew (2005), the global standard measures of affordability do not engage with housing issues. Importantly, these measures fail to take into account compromises that people make to lower housing costs, for instance, housing quality, location, transports choices and economic development. Therefore, this paper studies affordable housing issues that contribute to housing stress and well-being.

According to Collins English Dictionary the word "afford" means "being able to pay without incurring financial difficulties" (Robinson, et al. 2006). And the term "housing affordability" has come into a prevalent usage in the last 15years with different viewpoints. One such view suggests that people get a house where they want, with price they want, and at a place they deem appropriate (Disney, 2006). Other has suggested "housing is affordable when it consumes a reasonable or moderate amount of household income" (Kutty, 2005). Bhatta (2009) defined "affordable housing as housing that deemed affordable to those with a median household income as rated by country, province, region or municipality by a recognized Housing Affordability Index".

Psychologists define "affordability" as being able to pay without complaining from psychological, social, emotional, financial and mental stress. In fact, the term "affordability" is not an inherent characteristic of housing, but a relationship between household incomes, economic development, housing quality, neighbourhoods, and safety matter. According to Kribanandan \& Browne (1994), "affordable housing must be viewed as an integral part of an integrated housing and community development. Various elements must be taken into account before providing affordable house to the low and middle-income groups, for instance, building design and construction methods, culture, value system, and socio political elements, physical environmental elements and comfort levels, health, safety and security measures, income generating activities..." With this in mind, policy-makers must take all of these factors into account when discussing housing affordability.

\section{Housing Stress and Wellbeing}

King (1994) and Karmel (1998) indicated that the concept of "housing stress" has been of interest to government since 1990s. NAHP (2004) described it as a situation that "denotes the negative impacts for households with insufficient income to secure adequate housing..." Different studies signified the reasons "why housing stress could occur". The answer is because, firstly, the housing prices are getting higher and higher, particularly in the capital cities. And increment in housing price could produce issues as "affordable housing stress" (Baqutayan, 2014). The other reason is that, the quality of the houses is getting better, and the so call affordable housing is not safe and not liveable at all. According to Animashaun (2010), the housing problems vary from inadequate quantity and quality of housing to the attendant impact on the psychological, social, environmental and cultural aspects of housing. Furthermore, housing quality, size, location, neighbourhoods and household composition in any analysis of affordability seems to be very important measure of housing stress (Rowley \& Ong, 2012).

Housing price is not the only factor that contributes to housing stress, according to Evans, Kantrowitz \& Eshelman (2002), worries about house affordability and hazardous, unsafe conditions, concerns about maintenance, inadequate privacy, restrictions on children's play opportunities, and social stigma are among the factors that affect mental health and produces stress in families. According to Stone (2006) "Housing quality cannot be ignored. To what extend do households in accommodation considered affordable under traditional measures consume poor quality housing because there are no other alternatives?" The wider concept of "housing" and "affordability" need encompasses many of issues like housing size, quality, neighbourhood, location, and household composition (Stone, 2006).

More research signified that poor physical and mental health associated with physical and emotional housing stress (Dunn, 2002). Furthermore, Rowley \& Ong (2012) indicated that housing stress accounted for a significant portion of variance in measures of mental and physical health. And Dockery et al. (2010) documented that stress attributed to housing affordability problems was found to be associated with wellbeing. With this researcher will conclude this literature with the argent need to highlight the relationships between housing stress and overall wellbeing in Malaysia. 


\section{Methodology}

The study is purely based on a quantitative method that measures housing issues and its impact on wellbeing of the middle-income groups. The residents from middle-income groups were requested to answer the questionnaire that measures "housing issues and wellbeing". The sampling method was based on purposive sampling, focusing on middleincome housing areas.

\section{Results and Discussion}

\subsection{Demographic variable}

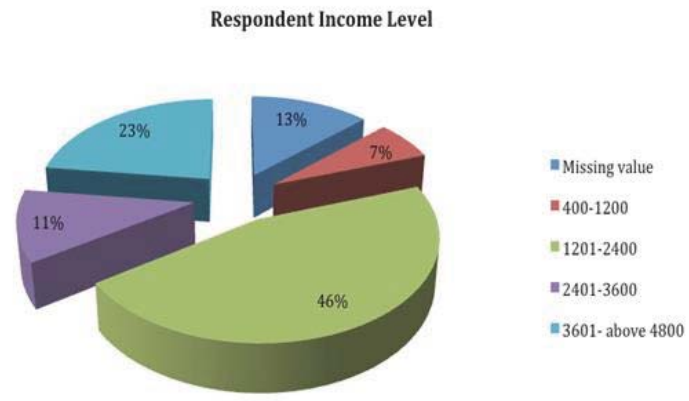

Figure 1: Respondent Income Level

The majority of respondents (46\%) earn between RM1201-RM2400 monthly, while an estimated 23\% per cent earn between RM 3601-4800, another $11 \%$ per cent is between RM 2401-3600, and the remaining 7\% per cent is between RM 400-1200, the other 13\% per cent is missing value. This signified that the salary average in Malaysia is very low; add into the fact that the big danger is the massive increase of housing price in Malaysia. According to Yin Shao Loong (2014), in 2013, the median salary for Malaysians was RM1700 per month. For non-Malaysians it was RM980. In 2013, $50 \%$ of Malaysians earned RM1700 and below per month. The largest share of household expenditure was spent on housing, water, electricity, gas and other fuels, followed by food and non-food beverages, transport, and restaurants. This outcome is very serious; when housing costs make up a large share of the household budget, and low/middle-income population is often constrained by the level of resources left for other necessary expenditures, such as food, healthcare and education. High housing costs can thus threaten wellbeing and economic security of the whole family. They may also generate forms of housing stress that may seriously hamper relations between all members of the house.

\subsection{Housing Price to Income Ratio}

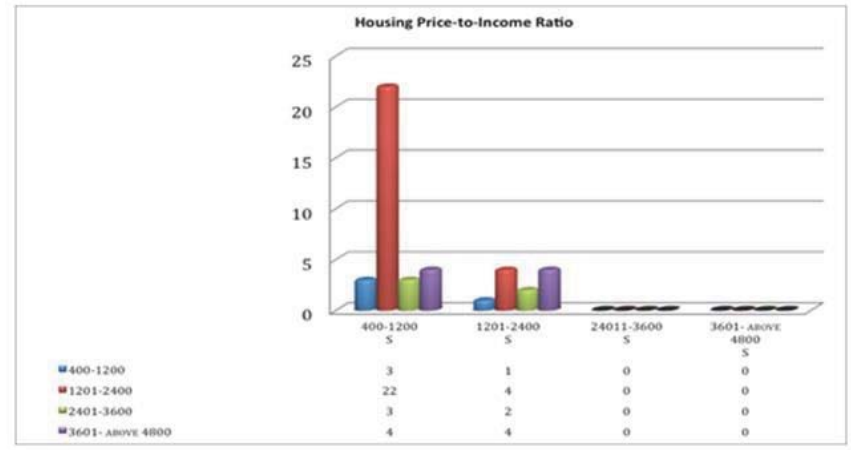

Figure 2: Housing Price To Income Ratio 
The above figure (2) showed that the majority pay rental between 400-1200 per-month in a house or in a room, and their income level is between 1201-2400. The lowest housing price-to-income ratio is almost more than $30 \%$ of the householder income. This indicated that there is a housing stress caused by housing rent. As stated in NCOSS (2014), that low and moderate income households are generally considered to be in housing stress when they have to pay more than $30 \%$ of their gross income on housing. Similarly stated by Darebin City Council (2010), that individuals and households who earn less than $80 \%$ of median income and who pay more than $30 \%$ of income are said to be in housing stress.

\subsection{Causes of Housing Stress among Middle-Income Group}

Table 1: Causes of Housing Stress

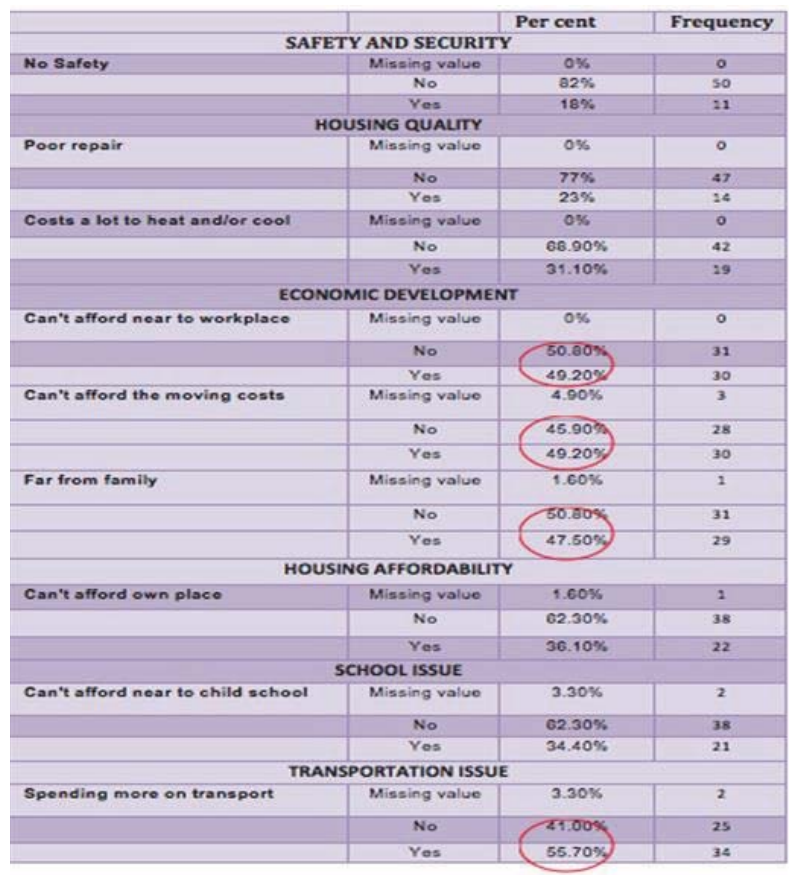

The above table showed that the majority complained about safety and security, housing quality and schools' availability. However they were complaining more about transportation cost and economic development. A significant percentage of respondents who answered "Yes" to all questions on "economic developments" were also indicated. Furthermore, some respondents complained about the distance, they are "not afford living near to the workplace" and they are "not afford the moving cost", therefore, they "live far from work and family". This outcome signified that "economic developments" add more burdens to every household; and that might lead to greater housing stress and emotional difficulties. Similarly was indicated by University of Western Sydney (2008), on the importance of housing locations and economic development. Distance was also found to be a significant predictor of housing stress (Kearns et al. 1992). Respondents in a study conducted by Dunn (2002) complained about transportation cost as a contributing factor to housing stress. A significant percentage of (55.70\%) of respondents answered "Yes" to the question on transportation. To conclude these outcomes, living closer to the workplace or having ease access to public transports are very important; it helps dwellers feel less stress and achieve peace of mind.

\section{Conclusion}

Housing conditions always have a direct impact on family incomes, which in turn significantly influence their level of 
stress and psychological wellbeing. The issues of housing stress and housing affordability are of major concern to many households; as majority of people concern about cost of living and housing pressures. This concern has grown rapidly, due to the increasing rate of housing prices and the possibility to find cheaper houses became almost impossible in the capital cities, mainly for low and middle-income groups.

The current research offers strong support for the view that if issues on affordable housing were increased the rate of housing stress would also increase. The main factors contributed to housing stress in this research are: housing price, safety and security, housing quality, transportation, school and economic development. The outcomes indicated that housing stress often occur not only in family who always pay more than $30 \%$ per cent of their income on housing, but also on those who spend more on transportation, living in an environment that is not safe, and staying far from office and families. The objective of this study was to analyse the main housing issue that contribute to the wellbeing. The findings indicated the following: (a) majority of the respondents were middle and low-household income, they monthly earn between RM1201-2400; (b) inconsistency between housing price, living cost and income ratio; (c) the majority complain about housing price; (d) housing affordability is an important factor of housing stress; (e) the other factors contributed to housing stress were transportation and economic development; (e) majority of respondents were not afford to live near to the workplace and they were also not afford the moving cost, thus, they live far from their workplace.

In conclusion, the present research findings can be used to tackle the affordable housing issues, and emphasizes on the need for more affordable housing that can be liveable. Keeping in mind that rising cost of living will create lots of stressors to people who tend to live in a condition whereby most of their expenses are going up every single year. Undeniably, affordable home has been linked with improving health outcomes for all people. Furthermore, the contribution of this study lies in the utilization of research data, in order to reduce issues related to affordable housing and adjust the living condition by taking the citizen well-being into account.

\section{References}

Animashaun, I. A. (2010). Provision of residential housing and environmental development in Calabar: Policy Contradictions. Retrieved from: http://www.readperiodicals.com/201001/2307422931.html

Barnes, M., et al, (2013). People living in bad housing - numbers and health impacts. NatCen Social Research. Retrieved April 2, 2015, from: http://england.shelter.org.ukl_data/assets/pdf_file/0010/726166/People_living_in_bad_housing.pdf

Baqutayan, S., (2014). The Affordable Housing Stress among Middle-Income Group. Journal Of Humanities And Social Science (IOSRJHSS) Volume 19 (7), 2014, PP 82-90.

Belsky, E., Goodman, J., \& Drew, R. (2005). Measuring The Nation's Rental Housing Affordability Problems. Retrieved April 2, 2015, from: http://www.jchs.harvard.edu/sites/jchs.harvard.edu/files/rd05-1_measuring_rental_affordability05.pdf

Bhatta, B. (2009), Analysis of urban growth pattern using remote sensing and GIS: a case study of Kolkata, India International Journal of Remote Sensing, 4733-4746

Darebin City Council (2010). Responding to housing stress A Local Action Plan for Darebin. Retrieved June 5, 2014, from: http://www.darebin.vic.gov.au/Files/6_September_2010_Item_8.4_Appendix_A_-_Darebin_Local_Action_Plan_on_Housing_ Stress.pdf

Department for Communities and Local Government (2012). National Planning Policy Framework. Retrieved April 7, 2015, from: https://www.gov.uk/government/uploads/system/uploads/attachment_data/file/6077/2116950.pdf

Disney, J. (2006). Over our heads: Housing costs \& Australian families. Australian Quarterly, 78(2), 4-11.

Dockery, AM, et al., (2010). Housing and children's development and wellbeing: A scoping study, Final Report No. 149, Australian Housing and Urban Research Institute, Melbourne.

Dunn, JR (2002). Housing and inequalities in health: A study of socioeconomic dimensions of housing and self-reported health from a survey of Vancouver residents. Journal of Epidemiology and Community Health, vol. 56, pp. 671- 681.

Evans, G. W., Kantrowitz, E., \& Eshelman, P. (2002). Housing quality and psychological well-being among the elderly population. Journals of Gerontology, Series B: Psychological Sciences and Social Sciences, 57, 381-383.

Jackson, R.J. (2003) 'The impact of the built environment on health: an emerging field', American Journal of Public Health, Vol. 93, No. 9, pp.1382-1384.

Karmel R., (1998). Housing assistance: Reports on measurement and data issues. Australian Housing and Urban Research Institute, Welfare Division Working Papers No. 17, Canberra.

Kearns, RA, Smith, CJ \& Abbott, MW (1992). The stress of incipient homelessness. Housing Studies, vol. 7, no. 4, pp. 280-298.

King, A., (1994). Towards indicators of housing stress, Department of Housing and Regional Development. Housing and Social Policy Group. Monograph series No. 2, AGPS, Canberra.

Kribanandan, G., \& Browne R D, (1994). Life Cycle Cost Design for Buildings \& Structures: A Strategic Initiative. MIGHT Forum on the Construction Industry, 4 February 1994, Kuala Lumpur, Malaysia.

Kutty, N.K., (2005). A new measure of housing affordability: Estimates and analytical results. Housing Policy Debate, 16 (1), pp.113-142.

Litman, T., (2015). Affordable-Accessible Housing In A Dynamic City: Why and How To Increase Affordable Housing Development In 
Accessible Locations. Victoria Transport Policy Institute. Retrieved April 6, 2015, from: http://www.vtpi.org/aff_acc_hou.pdf NAHP (2004). Housing Affordability: A Summary of Evidence and Issues in Measurement, National Affordable Housing Project, report prepared for AHURI and Policy Research Working Group.

NCOSS (2014). Affordable Housing: What we want \& background resources. Retrieved 3rd June, 2014, from: http://fairbruary.net/ resources/20140204affordable-housing-resources.pdf

NGA Center for Best Practice (2007). Policy Academy on Coordinating Housing and Economic Development Best Practices and Lessons Learned. Retrieved April 6, 2015, from: http://www.nga.org/files/live/sites/NGA/files/pdf/0701housingacademy. PDF;jsessionid=62987D7C7B16F3FF2F622730F8CA0A3A

Robinson, M., et al. (2006). Affordability of Housing: Concepts, Measurement and Evidence. Retrieved August 4, 2014, from: www.researchgate.net/...Affordability...HousingConcepts.../e0b49519bf.

Rowley, S. \& Ong, R., (2012). Housing affordability, housing stress and household wellbeing in Australia. Retrieved May 27, 2014, from: http://www.ahuri.edu.au/downloads/publications/EvRevReports/AHURI_Final_Report_No192_Housing_affordability_housing_stre ss_and_household_wellbeing_in_Australia.pdf

Stone, M. E. (2006). What is Housing Affordability? The Case for the Residual Income Approach. Housing Policy Debate, 17(1), 151184.

Yin Shao Loong (2014). Key Statistics. InstitutRakyat, 2014, 1 (1): 1-3. 